\title{
Asymmetric equilibria and non-cooperative access pricing in telecommunications
}

\author{
Stefan Behringer \\ Universität Bonn, \\ Adenauerallee 24-42, \\ Juridicum Raum 0.65, \\ 53113 Bonn, Germany \\ E-mail: behringe@uni-bonn.de
}

\begin{abstract}
This paper looks at competition in the telecommunications industry with non-linear tariffs and network-based price discrimination. Allowing for asymmetric networks and non-cooperatively chosen access prices simultaneously allows to explicitly derive non-reciprocal equilibrium access price choices that are above the efficient level and thus reconcile theory with regulatory practice.
\end{abstract}

Keywords: networks; telecommunications; competition policy; access pricing; regulation.

Reference to this paper should be made as follows: Behringer, S. (2012) 'Asymmetric equilibria and non-cooperative access pricing in telecommunications', Int. J. Management and Network Economics, Vol. 2, No. 3, pp.257-281.

Biographical notes: Stefan Behringer holds an MSc in Economics from the London School of Economics, a $\mathrm{PhD}$ from Universität Mannheim, and has been acting as Professor of Economics at Universities of Mainz and Bonn.

\section{Introduction}

The recent literature on network interconnection and pricing strategies in the telecommunications industry originating in the work of Armstrong (1998) and Laffont et al. (1998a, 1998b) has generically assumed that competition takes place between symmetric networks. Within this symmetric framework the analysis of Gans and King (2001) has shown that with non-linear tariffs and network-based price discrimination the optimal (i.e., profit-maximising) choice of negotiated and reciprocal access charges will imply a negative markup so that call termination is in fact subsidised.

These theoretical findings seem unable to explain the existing concern among competition authorities about such charges being 'too high' from a welfare perspective which is supported by results of Behringer (2009). The German Monopolkommission (2003, p.91) has published the following table for access charges (in cent per minute) charged by the mobile phone networks 


\begin{tabular}{llllll}
\hline & 1998 & 1999 & 2000 & 2001 & 2002 \\
\hline T-Mobile & 27.86 & 27.86 & 17.09 & 14.39 & 14.30 \\
Vodafone & 28.44 & 28.44 & 28.51 & 15.42 & 14.30 \\
E-Plus & 42.60 & 42.60 & 42.68 & 19.03 & 16.94 \\
$\mathrm{O}_{2}$ & 29.24 & 29.24 & 29.32 & 18.77 & 17.88 \\
\hline
\end{tabular}

These access charges were based on the individual firm's request for access to its network and are clearly non-reciprocal reflecting the fact that the former two were established incumbents and the latter two new entrants using a different transmission technology. The table covers the period before such charges were regulated directly. Based on a study by the Competition Commission for the UK, the Monopolkommission suggests that the cost for such termination services are only about half of the charges, i.e., between 7 and 7.8 cent and hence these charges are also clearly above cost.

This paper shows that one can indeed find non-reciprocal equilibrium access charges with a positive markup on termination cost by simultaneously assuming that such charges are chosen non-cooperatively and that networks are potentially asymmetric. It thus fills a critical gap in the literature as a tractable theoretical analysis of non-reciprocal access charges in asymmetric settings has been considered "one of the most valuable areas for future research" [see Armstrong, (2002), p.373].

Regarding the assumption of independence, as it is clearly in the interest of governments and consumers that mobile phone networks in fact do interconnect, regulatory agencies have not prevented negotiations over access prices per se. On the other hand these agencies are aware of the danger that such negotiations could spill over into negotiations of retail prices and hence they have not been mandated either as has been noted in Laffont et al. (1998a, p.13) already. Furthermore, access charges that are set non-cooperatively constitute the outside option of any interconnection agreement and they will also be relevant if considerations of deregulating mature telecommunications industries arise.

Visible outcomes of this access price setting process also suggests that firms do not seem to have set them according to the predictions of the pure cooperative price setting models. Consequently firms' concerns for private information regarding costs, technology, and pricing strategy as well as the mere complexity of such negotiations (which were required to succeed by law) may have prevented them from actively negotiating access charges in practice.

Non-cooperatively chosen access charges have been investigated previously by Gans and King (2001). In Proposition 1, in a symmetric setting they show that in equilibrium there will be a positive markup on termination cost. The latter has been argued to be related to the problem of 'double marginalisation' of complementary product pricing and has found its way into recent regulatory arguments [see for example, Rundfunk and Telekom Regulierungs GmbH, (2007), p.65]. The present paper, following the findings in Armstrong and Wright (2009) for the symmetric setting, argues that due to the presence of multi-part tariffs the reasons underlying the result are more complex.

The assumption of symmetry of the two networks in previous models is a most welcome simplifying device to keep the analysis of the pricing vectors that form the Nash equilibrium of the game tractable. However, in many cases of regulatory concern it is a new entrant who competes against an incumbent with an established market share and 
hence the assumption, being at the source of various 'neutrality results', see Laffont et al. (1998a) and Dessein (2003), seems to be unfortunate.

Previous research in asymmetric environments is scarce however. Carter and Wright (2003) is the most complete and the closest to our model but as Gans and King (2001) for the symmetric case, they are only able to show that firms would want to deviate from cost-based access prices and cannot give a prediction of how the asymmetry of the setting is reflected in the equilibrium non-cooperative access charges. Peitz (2005) also investigates the issue but focuses on the impact of asymmetric regulation. Dewenter and Haucap (2005) allow for consumers to be ignorant and know average prices only. Hoernig (2007) finds evidence that larger firms will tend to have a larger price differential between its on- and off-net prices but does not model access charges explicitly. A comprehensive collection of papers and a survey by Voung (2007) on asymmetry in mobile markets and references is Benzoni and Geoffron (2007).

The implications of such asymmetries on the initial major concern of regulatory agencies, i.e., the threat of collusion [see Höffler (2009) for the symmetric case] is investigated in Baranes et al. (2012). This paper allows for duopolistic competition with heterogenous demand elasticities. The implications of these asymmetries on the possibility to sustain collusion are investigated under alternative access pricing regimes. A similar generalisation is investigated in Jullien et al. (2010).

The present paper thus sets out to determine the profit-maximising choice of unregulated non-cooperative access prices of potentially asymmetric networks using the technology of Armstrong (1998). Whereas both, non-cooperative access and asymmetry have been investigated individually in previous workings, this is the first attempt to consider both features simultaneously. The model analysed represents, so far, the only robust method of generating non-reciprocal equilibrium off-net prices that are above the efficient level and allows, for the first time, to investigate the issue of how the asymmetry affects firms' optimal access pricing strategies and its regulatory implications.

\section{The model}

The setup builds upon Laffont et al. (1998b) in using a product differentiation model with mass one consumers distributed uniformly on the unit interval with two networks located at the extremes.

Using the technology of Armstrong (1998), the additively separable quadratic utility function of a consumer located at some $x$ from $[0,1]$ purchasing from network $j$ located at unity is

$$
u(q, x)=q\left(1-\frac{1}{2} q\right)+\eta x t
$$

with a horizontal preference parameter $t>0$ the benefit of which is independent of the amount of costly calls initiated $q$. We order the unit mass of consumers such that the difference of their 'address' $x$ to a network is proportional to their individual fixed benefit from being connected, with the consumer furthest away from the network at the origin receiving exactly zero fixed benefit. Hence, $t$ represents the maximum pure benefit of being connected to a network (without initiating any costly calls but including calls received) and is assumed to be exogenous. 
The asymmetry parameter is $\eta>0$, where $\eta>1$ implies an exogenous advantage for the (incumbent) network $j$ over network $i$ located at the origin whose consumers incur an exogenous benefit of $(1-x) t$. This advantage has a multiplicative feature and consumers that are located close to unity and use network $j$ 's services are, ceteris paribus, even more happy to do so if $\eta$ increases. This modelling of asymmetry has also successfully been applied in Geoffron and Wang (2008), and Baranes and Voung (2012).

This modelling is slightly different from Carter and Wright (2003) where the advantage is additive to the location and thus provides for 'vertical' differentiation that would affect preferences of all consumers from $j$ equally which is interpreted as 'brand loyalty' (or a simple switching cost). Here the asymmetry is introduced in a 'horizontal' way implying that the benefit difference between any two given consumers buying from $j$ strictly increases with an increase in $\eta$. Note that both specifications share the feature that within a simple Hotelling product differentiation model, a large asymmetry, again ceteris paribus, implies that the disadvantaged firm is driven out of the market.

A multiplicative advantage may similarly be interpreted as 'brand loyalty' but the degree to which this perceived benefit matters is proportional to the consumer's overall benefit of being connected to that network. In other words: a consumer of $j$ who derives very little benefit from being connected to $j$ will not be affected by $j$ 's efforts to increasing loyalty (or switching costs) to the same degree that a high valuations consumer of $j$ is.

Utility maximisation implies that individual demand for the service is

$$
q(p)=1-p
$$

which is analytically more convenient than the constant elasticity variant in Laffont, Rey and Tirole (LRT) and the indirect utility function is

$$
v(p) \equiv \int_{p}^{\infty} q(\xi) d \xi=q(p)\left(1-\frac{1}{2} q(p)\right)-p q(p)
$$

which (with $p \leq 1$ for non-negative quantities) is decreasing and strictly convex in price.

The networks use a two-part tariff consisting of a unit price (e.g., per minute of the service) $p$ and a fixed charge (e.g., a monthly rental charge) $G$ and thus the total per capita consumer $j$ valuation given location $x$ from $[0,1]$ is

$$
U_{x}=v(p)-G+\eta x t
$$

A consumer is indifferent between the two networks given his location $x$ from $[0,1]$ with networks using two-part tariffs and network-based price discrimination with on-net prices $p_{o n}$ and off-net prices $p_{\text {off }}$ if and only if the utility of this marginal consumer satisfies

$$
\begin{aligned}
U_{x} & =(1-x) v\left(p_{\text {on }}^{j}\right)+x v\left(p_{\text {off }}^{j}\right)-G^{j}+\eta x t \\
& =x v\left(p_{\text {on }}^{i}\right)+(1-x) v\left(p_{\text {off }}^{i}\right)-G^{i}+(1-x) t
\end{aligned}
$$

which we call the Hotelling indifference condition. The introduction of network-based price discrimination implies that despite interconnection there are 'tariff-mediated network externalities' present given that prices for on- and off-net calls differ. Consumers of network $i$ are better off if more consumers join the network if on-net prices are below 
off-net prices and vice versa. The location of the indifferent consumer who expects a given market share gives the network's equilibrium market shares if expectations are correctly fulfilled at the equilibrium price vector.

We specify marginal costs as $c \equiv 2 c_{0}+c_{1}<1$ for a call within one network resulting from origination and termination $\left(c_{0}\right)$ and the intermediate line service cost $c_{1}$ which we assume to occur at the originating end of the call. Network $i$ 's marginal cost for a call from its network to the other network are $c+a^{j}-c_{0}$ as it has to pay the access charge $a^{j}$ to network $j$, whereas the actual cost of the call is $c$ due to the networks' identical technologies. Firms also face a fixed cost $F>0$ and a per-capita cost $H>0$. Profits $\Pi^{k}$ of some firm $k$ are given by

$$
\begin{aligned}
\Pi^{k}= & m s^{k}\left[G^{k}-H+\left(p_{o n}^{k}-c\right) m s^{k} q_{o n}^{k}+\left(p_{o f f}^{k}-\left(c-a^{-k}-c_{0}\right)\right) m s^{-k} q_{o f f}^{k}\right] \\
& +m s^{k} m s^{-k}\left(a^{k}-c_{0}\right) q_{o f f}^{-k}-F
\end{aligned}
$$

where $m s^{k}$ from $(0,1)$ is $k$ 's market scale (where with two players $-k=j$ if $k=i$ or vice versa).

The two networks are assumed to be playing a non-cooperative two-stage game in which they first choose their optimal access price parameter $a^{k}$ simultaneously and in the second stage their price vector

$$
\Xi^{k}\left(a^{k}, a^{-k}\right) \equiv\left\{p_{o n}^{k}\left(a^{k}, a^{-k}\right), p_{o f f}^{k}\left(a^{k}, a^{-k}\right), G^{k}\left(a^{k}, a^{-k}\right)\right\}, \quad k=i, j
$$

simultaneously in order to maximise profits $\Pi^{k}\left(\Xi^{k}, \Xi^{-k}\right)$, taking as given the parameter vector of the other network. A vector $\Xi^{k}$ is a best response for player $k$ to his rivals' vector $\Xi^{-k}$ at this stage if

$$
\Pi^{k}\left(\Xi^{k}\left(a^{k}, a^{-k}\right) ; \Xi^{-k}\left(a^{k}, a^{-k}\right)\right) \geq \Pi^{k}\left(\Xi^{\prime k}\left(a^{k}, a^{-k}\right) ; \Xi^{-k}\left(a^{k}, a^{-k}\right)\right)
$$

for all $\Xi^{k}\left(a^{k}, a^{-k}\right) \neq \Xi^{k}\left(a^{k}, a^{-k}\right)$ in the multidimensional support of the price space.

The solution concept for the full game is pure strategy subgame perfect Nash-equilibrium (SPNE) and the game is solved by backward induction. The price vector $\Xi^{k}\left(a^{k}, a^{-k}\right)$ and the access charge $a^{k^{*}}$ constitute a subgame perfect Nash equilibrium strategy of the game if and only if for all $a^{k}$ and $k$,

$$
\begin{aligned}
& \Pi^{k}\left(\Xi^{k}\left(a^{k}, a^{-k}\right), a^{k^{*}} ; \Xi^{-k}\left(a^{-k}, a^{k}\right), a^{-k^{*}}\right) \\
& \geq \Pi^{k}\left(\Xi^{k}\left(a^{k}, a^{-k}\right), a^{k} ; \Xi^{-k}\left(a^{-k}, a^{k}\right), a^{-k^{*}}\right) .
\end{aligned}
$$

\section{Analysis}

Following the backward induction procedure we begin by solving the second stage of the game. Network $j$ will solve the programme

$$
\max _{\Xi^{j}}\left\{\Pi^{j}\left(\Xi^{j}, \Xi^{i}\right)\right\}=\max _{\Xi^{j}}\left\{\begin{array}{l}
(1-x) \times\left[\begin{array}{l}
G^{j}-H+\left(p_{o n}^{j}-c\right)(1-x) q_{o n}^{j} \\
+\left(p_{o f f}^{j}-\left(c+a^{i}-c_{0}\right)\right) x q_{o f f}^{j}
\end{array}\right] \\
+x(1-x)\left(a^{j}-c_{0}\right) q_{o f f}^{i}-F
\end{array}\right\}
$$


subject to the 'Hotelling indifference condition'

$$
x=\frac{v\left(p_{o n}^{j}\right)-v\left(p_{o f f}^{i}\right)-G^{j}+G^{i}-t}{v\left(p_{o n}^{i}\right)+v\left(p_{o n}^{j}\right)-v\left(p_{o f f}^{j}\right)-v\left(p_{\text {off }}^{i}\right)-t(1+\eta)}
$$

and given the vector $\Xi^{i}$ of network $i$. The choice of network $i$ with scale $x$ is symmetric.

Here $(1-x) q_{o n}^{j}$ gives the individual demand for on-net calls for a customer of network $j$ with scale or market share $(1-x)$. The pure termination profit for network $j$ under a balanced-traffic assumption is denoted as $x(1-x) \pi_{j}^{T}\left(a^{j}\right) \equiv x(1-x)\left(a^{j}-c_{0}\right) q_{o f f}^{i}$ as for equal off-net prices the percentage of cross-network calls will be the product of the fraction of the consumers on each network which is symmetric even if networks differ in their respective scales. However, only under reciprocal access charges does this assumption imply that payment flows between potentially asymmetric networks also balance.

A larger advantage for network $j$, i.e., a large choice of $\eta$ will then push the marginal consumer closer to the origin of the unit interval leading to a larger market share for the advantaged network. We first determine the network's optimal on-net and off-net prices.

Lemma 1: Any best response of network $i$ to network $j$ satisfies

$$
\Pi^{i}\left(p_{o n}^{i^{*}}=c, p_{o f f}^{i}, G^{i} ; \Xi^{j}\right) \geq \Pi^{i}\left(p_{o n}^{i}, p_{o f f}^{i}, G^{i} ; \Xi^{j}\right)
$$

for all $p_{o n}^{\prime i} \neq p_{o n}^{i *}$ in the support of the price vector space. Similarly, for given access charges $\bar{a}^{i}, \bar{a}^{j}$ any best response of network $i$ to network $j$ satisfies

$$
\Pi^{i}\left(p_{o n}^{i}, p_{o f f}^{i^{*}}=c_{0}+c_{1}+\bar{a}^{j}, G^{i} ; \Xi^{j}\right) \geq \Pi^{i}\left(p_{o n}^{i}, p_{o f f}^{\prime i}\left(\bar{a}^{j}\right), G^{i} ; \Xi^{j}\right)
$$

for all $p_{o f f}^{i} \neq p_{o f f}^{i^{*}}$ in the support of the price vector space. The symmetric result holds for network $j$.

Proof: Standard, see for example Laffont et al. (1998a) q.e.d.

We thus find that it is a (weakly) dominant strategy for any network to set its own on-net price and off-net price markup at the cost levels. In other words, setting the on-net price equal to cost, i.e., $p_{o n}^{k^{*}}=p_{o n}^{-k^{*}} \equiv p_{o n}^{*}=c$ and the off-net price of network $k$ equal to perceived marginal cost $p_{o f f}^{k^{*}}=c_{0}+c_{1}+\bar{a}^{-k}$ will be optimal for each network $k$ independently of the price vector of the other network $-k$ and not just for the equilibrium price vector as in a Nash equilibrium and thus does not require solving any additional equations.

We now proceed to calculate the equilibrium fixed charge for each network.

Proposition 2: Any best response in fixed charges of network $i$ must satisfy

$$
\begin{aligned}
G^{j}= & H+(1-4 x) v\left(p_{o n}^{*}\right)+2 x v\left(p_{o f f}^{j^{*}}\right)+(2 x-1) v\left(p_{o f f}^{i^{*}}\right) \\
& +(2 x-1) \pi_{T}^{i}\left(a^{i}\right)+(2 x(\eta+1)-1) t
\end{aligned}
$$


and any best response in fixed charges of network $j$ must satisfy

$$
\begin{aligned}
G^{i}= & H+(4 x-3) v\left(p_{\text {on }}^{*}\right)+2(1-x) v\left(p_{\text {off }}^{i^{*}}\right)+(1-2 x) v\left(p_{\text {off }}^{j^{*}}\right) \\
& +(1-2 x) \pi_{T}^{j}\left(a^{j}\right)+(2+\eta-2 x(\eta+1)) t
\end{aligned}
$$

where from the 'Hotelling indifference condition' (5)

$$
x\left(G^{i}, G^{j}\right)=\frac{v\left(p_{o n}^{*}\right)-v\left(p_{o f f}^{i^{*}}\right)-G^{j}+G^{i}-t}{2 v\left(p_{o n}^{*}\right)-v\left(p_{\text {off }}^{j^{*}}\right)-v\left(p_{\text {off }}^{i^{*}}\right)-t(1+\eta)}
$$

Proof: Network $j$ 's total profit is given as

$$
\Pi^{j}=\left\{\begin{array}{l}
(1-x)\left[\begin{array}{l}
(1-x)\left(v\left(p_{o n}^{j}\right)-v\left(p_{\text {off }}^{i}\right)\right)+x\left(v\left(p_{\text {off }}^{j}\right)-v\left(p_{\text {on }}^{i}\right)\right) \\
+t(x(1+\eta)-1)+G^{i}-H
\end{array}\right] \\
+x(1-x) \pi_{T}^{j}\left(a^{j}\right)-F
\end{array}\right\}
$$

where $x(1-x) \pi_{T}^{j}(a)$ denotes the termination profit of network $j$. We now take the derivative with respect to the optimal scale of network $j$

$$
\begin{aligned}
\frac{\partial \Pi^{j}}{\partial x}= & -\left[\begin{array}{l}
(1-x)\left(v\left(p_{\text {on }}^{j}\right)-v\left(p_{\text {off }}^{i}\right)\right)+x\left(v\left(p_{\text {off }}^{j}\right)-v\left(p_{\text {on }}^{i}\right)\right) \\
+t(x(1+\eta)-1)+G^{i}-H
\end{array}\right] \\
& +(1-x)\left[\left(v\left(p_{\text {off }}^{j}\right)-v\left(p_{\text {on }}^{i}\right)\right)-\left(v\left(p_{\text {on }}^{j}\right)-v\left(p_{\text {off }}^{i}\right)\right)+(1+\eta) t\right] \\
& +(1-2 x) \pi_{T}^{j}\left(a^{j}\right)=0
\end{aligned}
$$

which by using optimal pricing parameters and realising that $v\left(p_{o n}^{i *}\right)=v\left(p_{o n}^{j^{*}}\right)=v\left(p_{o n}^{*}\right)$, $j \neq i$ yields a condition for the best response $G^{j}\left(G^{i}\right)$ for firm $j$ with is implicit in $x\left(G^{i}\left(G^{j}\left(G^{i}\right)\right)\right.$. The proposition follows from symmetry and second order conditions will hold for $t$ and/or $\eta$ large enough as shown at the end of the Appendix. q.e.d.

The system of equations in the above proposition is linear and can be solved for its explicit solution which is unique but the expressions for the equilibrium fixed charges are quite involved and not necessary for what follows.

Taking the derivative with respect to scale and solving for it is isomorphic to the solution of the first order necessary condition for the optimal choice of the fixed charge (holding the other network's fixed charge constant) using their connection via the Hotelling indifference condition but more convenient, especially when we look at second order conditions below. Clearly the assumption of full market coverage allows us to interchange the scales of the two networks as choice variables of the first order necessary conditions.

As any equilibrium must satisfy the three equations in the previous proposition simultaneously we can derive the equilibrium scale of network $i$ (and thus of network $j$ ). The explicit derivations of equilibrium fixed charges can be found in the Appendix. 


\subsection{Multiple effects of symmetric access charges on profits}

From Lemma 1, we know that the maximisation programme is reduced to the sequential optimal choice of access charges and fixed charges. Thus, networks total profit at the first, access pricing stage of the game can be written as

$$
\Pi^{j}=\left(1-x^{*}\right)\left(G^{j^{*}}-H+x^{*} \pi_{T}^{j}\left(a^{j}\right)\right)-F
$$

and

$$
\Pi^{i}=x *\left(G^{i^{*}}-H+\left(1-x^{*}\right) \pi_{T}^{i}\left(a^{i}\right)\right)-F
$$

Taking the total derivative condition for finding an optimal access charge for network $i$ we find

$$
\frac{d \Pi^{i}}{d a^{i}}=\frac{\partial \Pi^{i}}{\partial a^{i}}+\frac{\partial \Pi^{i}}{\partial G^{i^{*}}} \frac{\partial G^{i^{*}}}{\partial a^{i}}+\frac{\partial \Pi^{i}}{\partial G^{j^{*}}} \frac{\partial G^{j^{*}}}{\partial a^{i}}=\frac{\partial \Pi^{i}}{\partial a^{i}}+\frac{\partial \Pi^{i}}{\partial G^{j^{*}}} \frac{\partial G^{j^{*}}}{\partial a^{i}}=0
$$

by the envelope condition. The 'direct effect' is given (for some given $G^{i^{*}}$ ) as

$$
\frac{\partial \Pi^{i}}{\partial a^{i}}=\frac{\partial x^{*}}{\partial a^{i}}\left(G^{i^{*}}-H+\left(1-2 x^{*}\right) \pi_{T}^{i}\left(a^{i}\right)\right)+x^{*}\left(1-x^{*}\right) \frac{\partial \pi_{T}^{i}\left(a^{i}\right)}{\partial a^{i}}
$$

The second part of the direct effect is resulting from the increase in termination profit and the first part from the increase in market share (holding constant both firms fixed charges) that results from the fact that higher access charges will be passed on to the consumers of the other network directly by an increase in the off-net price thus reducing their total benefit.

The 'indirect' or 'strategic effect' is given by

$$
\frac{\partial \Pi^{i}}{\partial G^{j^{*}}} \frac{\partial G^{j^{*}}}{\partial a^{i}}=\frac{\partial \Pi^{i}}{\partial G^{j^{*}}}\left(\frac{\partial G^{j^{*}}}{\partial v\left(p_{\text {off }}^{j}\right)} \frac{\partial v\left(p_{o f f}^{j}\right)}{\partial a^{i}}+\frac{\partial G^{j^{*}}}{\partial \pi_{T}^{i}\left(a^{i}\right)} \frac{\partial \pi_{T}^{i}\left(a^{i}\right)}{\partial a^{i}}\right)
$$

and describes how a change in the own access charge will influence own profits by the effect on the other network's optimal fixed charge.

In the symmetric case, with fixed access charges equal to cost the above optimality condition (15) reduces to

$$
\begin{aligned}
\left.\frac{d \Pi^{i}}{d a^{i}}\right|_{a^{i}=a^{j}=c_{0}} & =\frac{\partial x^{*}}{\partial a^{i}}\left(G^{i^{*}}-H\right)+\frac{1}{4} \frac{\partial \pi_{T}^{i}\left(a^{i}\right)}{\partial a^{i}}+\frac{\partial \Pi^{i}}{\partial G^{j^{*}}} \frac{\partial G^{j^{*}}}{\partial a^{i}} \\
& =\frac{1}{4} q_{o f f}^{j}\left(a^{i}\right)+\frac{1}{4} q_{o f f}^{j}\left(a^{i}\right)-\frac{1}{3} q_{o f f}^{j}\left(a^{i}\right)=\frac{1}{6} q_{o f f}^{j}\left(a^{i}\right)>0
\end{aligned}
$$

as shown in Armstrong and Wright (2008).

Based on the finding that this derivative is strictly positive with charges at cost, Gans and King (2001), Proposition 1, conclude that in any symmetric equilibrium the access charge will be strictly above cost and attribute this effect to a problem of 'double marginalisation'.

We also find that: 
Lemma 3: The equilibrium scale $x^{*}\left(a^{i}, a^{j}\right)$ is strictly increasing in access charge $a^{i}$ and decreasing in $a^{j}$ for equally advantaged networks and sufficiently large $t$.

Proof: see Appendix. q.e.d.

The intuition for this result is straightforward: A higher access charge raises the other network's perceived marginal cost that will be passed on to its consumers via the off-net call price thus moving the marginal consumer closer to the other network and increasing own market share and thus demand from the Hotelling indifference condition. The reverse holds for the other network's access charge. The change in relative optimal fixed charges will not counteract this effect for large enough $t$.

If networks are strongly asymmetric it may be that an advantaged network's scale is still increasing in its optimal access charge parameter but that of the disadvantaged network is not. Here an increase in the access charge charged to the advantaged network can change the optimal fixed charge such that the own scale is in fact decreasing. The same may happen if networks are not sufficiently differentiated.

Lemma 4: Higher access charges $a^{i}, a^{j}$ increase demand cross-elasticities for sufficiently large $t$.

Proof: see Appendix. q.e.d.

We show that calls from firm $i$ and on-net calls of firm $j$ are complementary and that calls from firm $i$ and off-net calls of firm $j$ are substitute products. As a sufficiently large $t$ limits the effects of changing prices on equilibrium scales but a higher access charge is directly passed on via higher off-net prices demand cross-elasticities increase. This implies that with higher access charges calls from one firm become better substitutes for calls from the other firm.

\subsection{Large asymmetries}

What happens if the advantage of the incumbent is very strong? We first find the following result:

Lemma 5: The equilibrium scale $x^{*}\left(a^{i}, a^{j}\right)$ is strictly decreasing in $\eta$ and has a strictly positive lower bound for sufficiently large $t$.

Proof: see Appendix. q.e.d.

Given our specification of asymmetry, a higher inequality parameter $\eta$ pivots the fixed benefit line such that those consumers close to the incumbent receive more extra benefit than those that are marginal. Hence, there will be a trade-off for each network: on the one hand, having a larger scale allows to collect more per capita fixed fees from consumers. On the other hand giving up on some consumers allows to extract an even higher fixed fee from those that are infra-marginal, and it is the latter effect that dominates at large $\eta$ and implies a strictly positive lower bound.

This lemma has an important implication for the form that competition between two networks takes. For any magnitude of the relative initial advantage of one of the two networks (possibly the incumbent), there is always a strictly positive market share larger than one-third of the market for the second network which is unlike in the standard Hotelling model where, ceteris paribus, a large advantage of one firm drives the other out of the market. 
Having a higher access revenue (resulting from higher access charges) will make the advantaged firm (the incumbent) a softer competitor. Having a large advantage by the previous lemma implies that the network will already have a large scale and hence obtain much of the total per-capita fixed fee revenue. If the weight of the termination profit term $\pi_{T}^{k}\left(a^{k}\right), k=i, j$ in the profit functions is increased, a large firm will be more willing to tolerate a slightly lower share of the fixed fee revenue for a higher share of the termination revenue resulting from a higher cross-scale traffic term. By analogy, the disadvantaged firm $i$ (the entrant) is a tougher competitor trying to increase $x$ more vigorously (by some, $a^{i}, G^{i}$ combination) than the advantaged firm $j$ (the incumbent) tries to decrease $x$ further.

Note that these findings do not depend on the simple linear demand specification we have used but also holds in the setting of LRT with constant elasticity demand. A constant elasticity setting does not allow us to check for second order sufficient conditions when we consider potentially asymmetric equilibria however. This can be done using our linear demand specification and is undertaken at the end of the Appendix.

We also find that:

Lemma 6: If the advantage of network $j(\eta>1)$ is large, demand elasticity is reduced.

Proof: see Appendix. q.e.d.

We then find that contrary to previous attempts using a linear technology we can approximate the limit access charges explicitly:

Lemma 7: If the advantage of network $j(\eta>1)$ is large, non-cooperative access charges are approximately equal to

$$
\Delta^{j^{*}} \equiv a^{j^{*}}-c_{0} \approx \frac{1}{2}(1-c)>0
$$

and

$$
\Delta^{i^{*}} \equiv a^{i^{*}}-c_{0} \approx \frac{2}{7}(1-c)>0
$$

Proof: see Appendix. q.e.d.

With large $\eta$, optimal scales converge to a strictly positive constant and hence the incumbent's residual demand elasticities go to zero. As a first intuition find that this seems to be supported by the fact that what the network may gain in terms of market share by changing the access charge decreases to zero and thus the incumbent will simply charge the monopoly termination charge. However, this neglects the effect that the access charge has on the equilibrium fixed charge of the other network and also the pure termination profit itself.

For the entrant on the other hand a high access charge implies that it will be tougher relative to the incumbent, i.e., pricing more aggressively and hence losing out on profits. With a large advantage for the incumbent, this strategic effect dominates and in order to avoid being tough the entrant will set its access charge below the monopoly rate in order to be a softer competitor in fixed charges.

The details underlying these effects are investigated in the next section. 
We are also able to look at the components of each firm's price vector for extreme asymmetry. We find the following result:

Lemma 8: If the advantage of network $j(\eta>1)$ is large we find that the components of the price vectors satisfy

$$
\Delta^{j}>\Delta^{i}
$$

and

$$
\pi_{T}^{j}\left(a^{j}\right)>\pi_{T}^{i}\left(a^{i}\right)
$$

and

$$
G^{j}>G^{i}
$$

and

$$
\Pi^{j}>\Pi^{i} .
$$

Proof: see Appendix. q.e.d.

The analysis thus shows that for large asymmetries a disadvantaged network which targets a smaller market scale will choose a relatively lower access charge markup than an advantaged network. On the other hand, a disadvantaged firm will also set a lower fixed charge negating any 'waterbed' effect in this strongly asymmetric setting. This theoretical result on markups emphasises the role of the different marginal costs (of the entrants' GSM 1,800 MHz versus the incumbents' GSM $900 \mathrm{MHz}$ technology in the introduction) which will influence the empirical magnitude of access charge differences (see Ofcom, 2004).

\subsection{Multiple limit effects of asymmetric access}

The above decomposition of different effects of symmetric access charges on profits can be investigated for the large asymmetry case also. This is done in the following section. Analogous to (15) we first have for the disadvantaged firm that

$$
\begin{aligned}
\frac{d \Pi^{i}}{d a^{i}}= & \frac{\partial x^{*}}{\partial a^{i}}\left(G^{i^{*}}-H+\left(1-2 x^{*}\right) \pi_{T}^{i}\left(a^{i}\right)\right)+x^{*}\left(1-x^{*}\right) \frac{\partial \pi_{T}^{i}\left(a^{i}\right)}{\partial a^{i}} \\
& +\frac{\partial \Pi^{i}}{\partial G^{j^{*}}}\left(\frac{\partial G^{j^{*}}}{\partial v\left(p_{\text {off }}^{j}\right)} \frac{\partial v\left(p_{o f f}^{j}\right)}{\partial a^{i}}+\frac{\partial G^{j^{*}}}{\partial \pi_{T}^{i}\left(a^{i}\right)} \frac{\partial \pi_{T}^{i}\left(a^{i}\right)}{\partial a^{i}}\right)=0
\end{aligned}
$$

has to hold.

The individual limits exist and the limit effect can be calculated as: the direct increase in termination profit

$$
\lim _{\eta \rightarrow \infty}\left(\frac{\partial x^{*}}{\partial a^{i}}\left(x^{*}\left(1-x^{*}\right) \frac{\partial \pi_{T}^{i}\left(a^{i}\right)}{\partial a^{i}}\right)=\frac{2}{9} \frac{\partial \pi_{T}^{i}\left(a^{i}\right)}{\partial a^{i}}\right.
$$

the direct increase in market share (holding constant both firms fixed charges) 


$$
\lim _{\eta \rightarrow \infty}\left(\frac{\partial x^{*}}{\partial a^{i}}\left(G^{i^{*}}-H+\left(1-2 x^{*}\right) \pi_{T}^{i}\left(a^{i}\right)\right)\right)=\frac{1}{9} q_{o f f}^{j}\left(a^{i}\right)
$$

and the indirect limit effect

$$
\begin{aligned}
& \lim _{\eta \rightarrow \infty}\left(\frac{\partial \Pi^{i}}{\partial G^{j^{*}}}\left(\frac{\partial G^{j^{*}}}{\partial v\left(p_{\text {off }}^{j}\right)} \frac{\partial v\left(p_{\text {off }}^{j}\right)}{\partial a^{i}}+\frac{\partial G^{j^{*}}}{\partial \pi_{T}^{i}\left(a^{i}\right)} \frac{\partial \pi_{T}^{i}\left(a^{i}\right)}{\partial a^{i}}\right)\right) \\
& =\frac{1}{3}\left(\frac{2}{3} \frac{\partial v\left(p_{\text {off }}^{j}\right)}{\partial a^{i}}-\frac{1}{9} \frac{\partial \pi_{T}^{i}\left(a^{i}\right)}{\partial a^{i}}\right)
\end{aligned}
$$

which, for an increase in $a^{i}$ describes how the resulting higher off-net price of $j$, will be accommodated by a lower optimal fixed charge $G^{j^{*}}$ that will lead to a lower scale $x^{*}$ and thus has an indirect effect on $i$ 's profits.

As a check of result (20), i.e., the optimal access price of the disadvantaged firm, one finds the necessary condition

$$
\begin{aligned}
\frac{d \Pi^{i}}{d a^{i}} & =\frac{1}{9} q_{o f f}^{j}\left(a^{i}\right)+\frac{2}{9} \frac{\partial \pi_{T}^{i}\left(a^{i}\right)}{\partial a^{i}}+\frac{1}{3}\left(\frac{2}{3} \frac{\partial v\left(p_{o f f}^{j}\right)}{\partial a^{i}}-\frac{1}{9} \frac{\partial \pi_{T}^{i}\left(a^{i}\right)}{\partial a^{i}}\right) \\
& =\frac{5}{27} \frac{\partial \pi_{T}^{i}\left(a^{i}\right)}{\partial a^{i}}-\frac{1}{9} q_{o f f}^{j}\left(a^{i}\right)=0
\end{aligned}
$$

in equilibrium. For the given linear specification this results in

$$
\frac{5}{27}\left(1-c_{1}-2 a^{i}\right)-\frac{1}{9}\left(1-\left(c_{0}+c_{1}+a^{i}\right)\right)=0
$$

which is indeed solved by

$$
a^{i}-c_{0}=\frac{2}{7}(1-c)>0
$$

Lemma 9: There exist a solution to (25) for general demand forms such that $a^{i}$ is within the cost (zero markup) and the monopoly level.

Proof: see Appendix. q.e.d.

For the advantaged firm $j$ we find the following result:

$$
\begin{aligned}
\frac{d \Pi^{j}}{d a^{j}}= & -\frac{\partial x^{*}}{\partial a^{j}}\left(G^{j^{*}}-H+2 x^{*} \pi_{T}^{j}\left(a^{j}\right)\right)+\left(1-x^{*}\right) x * \frac{\partial \pi_{T}^{j}\left(a^{j}\right)}{\partial a^{j}} \\
& +\frac{\partial \Pi^{j}}{\partial G^{i^{*}}}\left(\frac{\partial G^{i^{*}}}{\partial v\left(p_{\text {off }}^{i}\right)} \frac{\partial v\left(p_{o f f}^{i}\right)}{\partial a^{j}}+\frac{\partial G^{i^{*}}}{\partial \pi_{T}^{j}\left(a^{j}\right)} \frac{\partial \pi_{T}^{j}\left(a^{j}\right)}{\partial a^{j}}\right)=0
\end{aligned}
$$

by the envelope condition.

The three limit effects are the direct increase in termination profit

$$
\lim _{\eta \rightarrow \infty}\left(\left(1-x^{*}\right) x * \frac{\partial \pi_{T}^{j}\left(a^{j}\right)}{\partial a^{j}}\right)=\frac{1}{3} \frac{2}{3} \frac{\partial \pi_{T}^{j}\left(a^{j}\right)}{\partial a^{j}}=\frac{2}{9} \frac{\partial \pi_{T}^{j}\left(a^{j}\right)}{\partial a^{j}}
$$


which reveals the same cross-product term as that for the disadvantaged firm. More involved to calculate are the direct increase in market share effect

$$
\lim _{\eta \rightarrow \infty}\left(-\frac{\partial x^{*}}{\partial a^{j}}\left(G^{j^{*}}-H+2 x^{*} \pi_{T}^{j}\left(a^{j}\right)\right)\right)=\frac{4}{9} q_{o f f}^{i}\left(a^{j}\right)
$$

which has more weight than that for the disadvantaged firm. Finally the indirect effect

$$
\begin{aligned}
& \lim _{\eta \rightarrow \infty}\left(\frac{\partial \Pi^{j}}{\partial G^{i^{*}}}\left(\frac{\partial G^{i^{*}}}{\partial v\left(p_{o f f}^{i}\right)} \frac{\partial v\left(p_{o f f}^{i}\right)}{\partial a^{j}}+\frac{\partial G^{i^{*}}}{\partial \pi_{T}^{j}\left(a^{j}\right)} \frac{\partial \pi_{T}^{j}\left(a^{j}\right)}{\partial a^{j}}\right)\right) \\
& =\frac{2}{3}\left(\frac{2}{3} \frac{\partial v\left(p_{o f f}^{i}\right)}{\partial a^{j}}+\frac{1}{9} \frac{\partial \pi_{T}^{j}\left(a^{j}\right)}{\partial a^{j}}\right)
\end{aligned}
$$

that is also more pronounced for the advantaged firm with weights given by own scales. We thus find

$$
\begin{aligned}
\frac{d \Pi^{j}}{d a^{j}} & =\frac{4}{9} q_{o f f}^{i}\left(a^{j}\right)+\frac{2}{9} \frac{\partial \pi_{T}^{j}\left(a^{j}\right)}{\partial a^{j}}+\frac{2}{3}\left(\frac{2}{3} \frac{\partial v\left(p_{o f f}^{i}\right)}{\partial a^{j}}+\frac{1}{9} \frac{\partial \pi_{T}^{j}\left(a^{j}\right)}{\partial a^{j}}\right) \\
& =\frac{8}{27} \frac{\partial \pi_{T}^{j}\left(a^{j}\right)}{\partial a^{j}}=0
\end{aligned}
$$

and it is interesting to note that the effect of $q_{o f f}^{i}\left(a^{j}\right)$ on this optimality condition cancel out completely so that the condition for the given linear specification is indeed solved by the monopoly termination charge (19)

$$
a^{j}-c_{0}=\frac{1}{2}(1-c)>0 .
$$

In other words, the positive own market share effect on profit that an increase in the access charge to the other firm implies will be exactly offset by the negative first part of the indirect effect on profit, i.e., the effect that an increase has on the other firm's optimal fixed charge (via the lower indirect utility for off-net calls from the other network) and hence the condition becomes identical to the pure monopoly termination profit maximising condition. The advantaged firm will act as if its choice of the access charge did not have any implication for the other equilibrium magnitudes.

These decompositions allow for a comparison with the symmetric case which has been investigated in Armstrong and Wright (2009). They show that the independently chosen symmetric termination charge has to satisfy the necessary first-order condition

$$
\begin{aligned}
\left.\frac{d \Pi^{i}}{d a^{i}}\right|_{a^{i}=a^{j}=a}= & \left.\frac{\partial \Pi^{i}}{\partial a^{i}}\right|_{a^{i}=a^{j}=a}+\left.\frac{\partial \Pi^{i}}{\partial G^{j^{*}}} \frac{\partial G^{j^{*}}}{\partial a^{i}}\right|_{a^{i}=a^{j}=a} \\
= & \frac{1}{4} \frac{\partial \pi_{T}(a)}{\partial a}+\frac{1}{4} q_{\text {off }}(a) \\
& -\frac{q_{\text {off }}(a)}{4} \frac{4 t+4 v\left(p_{\text {off }}(a)\right)-4 v\left(p_{\text {on }}\right)+3 \pi_{T}(a)}{3 t+3 v\left(p_{\text {off }}(a)\right)-3 v\left(p_{\text {on }}\right)+2 \pi_{T}(a)}=0
\end{aligned}
$$

The equilibrium termination charge thus has to satisfy 


$$
\frac{\partial \pi_{T}(a)}{\partial a}=q_{o f f}(a) \frac{t+v\left(p_{o f f}(a)\right)-v\left(p_{o n}\right)+\pi_{T}(a)}{3 t+3 v\left(p_{o f f}(a)\right)-3 v\left(p_{o n}\right)+2 \pi_{T}(a)}
$$

but even for our simple linear specification an explicit solution is involved. As Armstrong and Wright (2008) note, (35) can be rewritten as

$$
\frac{\frac{\partial \pi_{T}(a)}{\partial a}}{q_{\text {off }}(a)}=\frac{t+v\left(p_{\text {off }}(a)\right)-v\left(p_{\text {on }}\right)+\pi_{T}(a)}{3\left(t+v\left(p_{\text {off }}(a)\right)-v\left(p_{\text {on }}\right)\right)+2 \pi_{T}(a)}
$$

And if $a=c_{0}$ this reduces to

$$
\left.\frac{\frac{\partial \pi_{T}(a)}{\partial a}}{q_{\text {off }}(a)}\right|_{a=c_{0}}=1>\left.\frac{t+v\left(p_{\text {off }}(a)\right)-v\left(p_{\text {on }}\right)+\pi_{T}(a)}{3\left(t+v\left(p_{\text {off }}(a)\right)-v\left(p_{\text {on }}\right)\right)+2 \pi_{T}(a)}\right|_{a=c_{0}}=\frac{1}{3}
$$

whereas at the monopoly charge the LHS is zero by definition. Here the RHS is positive by the satisfaction of the second order condition [see (91)] and thus the equilibrium termination charge exists in between. Given our linear specification, the LHS of (36) is decreasing in $a$. The derivative of the RHS is

$$
\frac{\left(t+v\left(p_{\text {off }}(a)\right)-v\left(p_{\text {on }}\right)\right) \frac{\partial \pi_{T}(a)}{\partial a}+q_{\text {off }}(a) \pi_{T}(a)}{\left(3\left(t+v\left(p_{\text {off }}(a)\right)-v\left(p_{\text {on }}\right)\right)+2 \pi_{T}(a)\right)^{2}}>0
$$

i.e., positive by the satisfaction of the second order condition [see (91)] as $\partial \pi_{T}(a) / \partial a \geq 0$ in the relevant range. Hence there exists a unique optimal access charge that satisfies the condition (36) in the symmetric case.

\section{Equilibrium}

Performing a local analysis around the symmetric equilibrium using a Taylor approximation we find that:

Proposition 10: At the symmetric equilibrium $\eta=1$ both firms will charge a strictly positive non-cooperative access charge markup. In a neighbourhood of the symmetric equilibrium an advantaged network charges a relatively higher access charge.

Proof: see Appendix. q.e.d.

Again we find the same underlying effects as above: A higher access charges implies that the entrant will be tougher relative to the incumbent, i.e., pricing more aggressively in the fixed charge dimension. Even with only a small relative advantage for the incumbent this strategic effect dominates and the slightly smaller entrant will set its access charge below that of the incumbent in order not to be the tougher competitor.

We therefore find that, as in the investigations of the symmetric setting, the non-cooperative access charge markup with asymmetric networks is positive, both in the limit analysis (where contrary to the previous attempts a limiting access charge can be 
approximated) and in the local analysis around the symmetric equilibrium case $\eta=1$. This result may be contrasted with that of Carter and Wright (2003, Proposition 1) for reciprocal access charges and an alternative specification of asymmetry where both firms, a very small and a large firm prefer a zero markup.

Interestingly in both analyses, given a relative advantage $\eta \neq 1$ for any network, an advantaged network having the larger market share will optimally choose a relatively larger access charge than a disadvantaged network both if the advantage is small and if the advantage is very large.

At the end of the Appendix we show in two further lemmata the conditions under which the second order necessary conditions hold, i.e., that the vector of potentially asymmetric pricing parameters $\Xi^{*}$ is indeed maximising the profit of each network for any access charges given that the pure benefit of being connected $t$ is sufficiently large and/or the degree of asymmetry $\eta$ is sufficiently large.

\section{Conclusions}

In the preceding analysis we find that the simultaneous introduction of potential asymmetry and of non-cooperatively chosen access prices will lead to above-cost, non-reciprocal equilibrium off-net prices that are above the efficient level. The reasons underlying these findings are more complex than in the standard 'double marginalisation' problem of complementary duopoly product competition due to the presence of multi-part tariffs.

In fact, the above analysis presents the only robust analytical way of generating such prices so far. Contrary to the previous literature, in an asymmetric setting where one network competes at a perceived disadvantage proportional to consumer's fixed benefit we are able to approximate this markup explicitly. We are thus able to bring the theoretical analysis in line with regulatory concern. Extending the analysis to asymmetric settings, which are highly prevalent in practice, we are able to shed light on questions of optimal independent pricing behaviour that were previously left open and that have implications for the nature of possible negotiated access pricing and for eventual deregulation in mature industries.

Unlike in the simple Hotelling model of horizontal product differentiation the advantaged network will not cover the full market, no matter how large the relative advantage becomes. This implies that due to the complexity of the optimal pricing strategy involved, the telecommunications market may be more 'contestable' than previous studies have suggested. Additionally, we find that for a sufficiently pronounced asymmetry, optimal fixed charges and profits for both firms are increasing in the asymmetry parameter, i.e., that due to the strategic interaction of the firms the advantage and the implied asymmetry becomes an advantage for the 'disadvantaged' firm too.

We eventually find that around the symmetric equilibrium the disadvantaged network will optimally set access charge markup below that of an advantaged network covering a larger market in the asymmetric equilibrium which is also the case for large asymmetries. This finding results from the strategic desire of the smaller entrant to avoid being the tougher competitor in fixed charges. Having a lower access charge relative to the incumbent implies that the latter has a higher incentive to give up scale in order to increase total cross-network traffic and hence termination revenue and thus will be a softer competitor relative to the entrant. 


\section{Acknowledgements}

The author would like to thank Mark Armstrong, Martin Hellwig, Felix Höffler, Steffen Hoernig, Klaus Holthoff-Frank, Bruno Jullien, participants of the 2006 'Competition Policy in Two-Sided Markets' Conference in Toulouse, the referees, and importantly Julian Wright for comments.

\section{References}

Armstrong, M. (1998) 'Network interconnection in telecommunications', Economic Journal, Vol. 108, pp.545-564.

Armstrong, M. (2002) 'The theory of access pricing and interconnection', in Cave, M.E., Majumdar, S. and Vogelsang, I. (Eds.): Handbook of Telecommunications Economics, Vol. 1, pp.295-386, Amsterdam, North Holland.

Armstrong, M. and Wright, J. (2009) 'Mobile call termination', Economic Journal, June, Vol. 119, pp. 270-307.

Baranes, E. and Voung, C.H. (2012) 'Competition with asymmetric regulation of mobile termination charges', Journal of Regulatory Economics, (forthcoming), DOI 10.1007/s11149011-9171-2.

Baranes, E., Behringer, S. and Poudou, J-C. (2012) Mobile Call Termination and Collusion under Asymmetry, mimeo.

Behringer, S. (2009) 'Entry, access pricing, and welfare in the telecommunications industry', Economics Letters, Vol. 102, No. 3, pp.185-188.

Benzoni, L. and Geoffron, P. (Eds.) (2007) Competition and Regulation with Asymmetries in Mobile Markets, Quantifica Editions, Paris.

Carter, M. and Wright, J. (2003) 'Asymmetric network interconnection', Review of Industrial Organization, Vol. 22, No. 1, pp.27-46.

Dessein, W. (2003) 'Network competition in nonlinear pricing', RAND Journal of Economics, Vol. 34, No. 4, pp.593-611.

Dewenter, R. and Haucap, J. (2005) 'The effects of regulating mobile termination rates for asymmetric networks', European Journal of Law and Economics, Vol. 20, No. 2, pp.185-197.

Gans, J. and King, S. (2001) 'Using 'bill and keep' interconnect agreements to soften network competition', Economic Letters, Vol. 71, No. 3, pp.413-420.

Geoffron, P. and Wang, H. (2008) 'What is the mobile termination regime for the asymmetric firms with a calling club effect?', Int. J. Management and Network Economics, Vol. 1, No. 1, pp.58-79.

Hoernig, S. (2007) 'On-net and off-net pricing on asymmetric telecommunications networks', Information Economics and Policy, June, Vol. 19, No. 2, pp.171-188.

Höffler, F. (2009) 'Mobile termination and collusion, revisited', Journal of Regulatory Economics, Vol. 35, No. 3, pp.246-274.

Jullien, B., Rey, P. and Sand-Zantman, W. (2010) 'Mobile call termination revisited', IDEI Working Paper No. 551.

Laffont, J-J., Rey, P. and Tirole, J. (1998a) 'Network competition: I. Overview and non-discriminatory pricing', RAND Journal of Economics, No. 1, pp.1-37.

Laffont, J-J., Rey, P. and Tirole, J. (1998b) 'Network competition: II. Price discrimination', RAND Journal of Economics, No. 1, pp.38-56.

Monopolkommission (2003) 'Sondergutachten Telekommunikation und Post 2003', available at http://www.monopolkommission.de/sg_39/text_s39.pdf (accessed on 16 January 2012). 
Ofcom (2004) 'Wholesale mobile voice call termination', available at http://stakeholders.ofcom. org.uk/consultations/mobile_call_termination/ (accessed on 16 January 2010).

Peitz, M. (2005) 'Asymmetric regulation of access and price discriminations', Journal of Regulatory Economics, Vol. 28, No. 3, pp.327-343.

Rundfunk and Telekom Regulierungs GmbH (2007) 'Bescheid der TKK vom 15.10.2007', available at http://www.rtr.at/de/tk/Mobilterminierung/M15a_03_M13a_06_Mobilkom.pdf (accessed on 16 January 2012).

Voung, C.H. (2007) 'Asymmetric theory of access pricing in mobile telephony', in Benzoni, L. and Geoffron, P. (Eds.): Competition and Regulation with Asymmetries in Mobile Markets, Quantifica Editions, Paris.

\section{Appendix}

Simplifying notation as $v\left(p_{\text {off }}^{k^{*}}\right)=v\left(p_{\text {off }}^{k^{*}}\left(a^{-k}\right)\right) \equiv v_{-k}, v\left(p_{o n}\right) \equiv v$ and $\pi_{T}^{k}\left(a^{k}\right) \equiv \pi_{T}^{k}$ with $-k=j$ if $k=i$ or vice versa. The equilibrium fixed charges and scale as given in Proposition 2 can be calculated explicitly as

$$
\begin{aligned}
& G^{j^{*}}= \frac{2 t^{2} \eta^{2}+t^{2}+2 v_{i}{ }^{2}+v_{j}{ }^{2}-7 v t \eta+2 \pi_{T}^{j} t \eta+4 v_{i} t \eta-7 v v_{i}}{3\left(v_{i}+v_{j}-2 v\right)+3 t(1+\eta)+2\left(\pi_{T}^{i}+\pi_{T}^{j}\right)} \\
& G^{2} \eta^{2}+2 t^{2}+v_{i}^{2}+2 v_{j}^{2}-7 v t+2 \pi_{T}^{i} t+2 v_{i} t \eta-7 v v_{j}-5 v v_{i} \\
& G^{i *}=\frac{-5 v t \eta+4 v_{j} t+2 \pi_{T}^{i} v_{j}+\pi_{T}^{j}\left(v_{i}+v_{j}+t+t \eta\right)+\Psi}{3\left(v_{i}+v_{j}-2 v\right)+3 t(1+\eta)+2\left(\pi_{T}^{i}+\pi_{T}^{j}\right)}
\end{aligned}
$$

where

$$
\begin{aligned}
\Psi \equiv & 6 v^{2}+3 H v_{i}+3 v_{i} v_{j}+3 v_{i} t+3 v_{j} t \eta-2 v \pi_{T}^{j}-2 v \pi_{T}^{i} \\
& +3 t H+3 v_{j} H-6 v H+3 t^{2} \eta+2 H \pi_{T}^{i}+2 H \pi_{T}^{j}+3 H t \eta
\end{aligned}
$$

and

$$
x^{*}=\frac{v_{i}+2 v_{j}-3 v+2 t+t \eta+\pi_{T}^{i}+\pi_{T}^{j}}{3\left(v_{i}+v_{j}-2 v\right)+3 t(1+\eta)+2\left(\pi_{T}^{i}+\pi_{T}^{j}\right)}
$$

Proof of Lemma 3: From (41) we have the equilibrium scale as

$$
\begin{aligned}
& -3 v\left(p_{o n}^{*}\right)+2 v\left(p_{o f f}^{i^{*}}\left(a^{j}\right)\right)+v\left(p_{o f f}^{j^{*}}\left(a^{i}\right)\right) \\
x *\left(a^{i}, a^{j}\right)= & \frac{+\pi_{T}^{i}\left(a^{i}\right)+\pi_{T}^{j}\left(a^{j}\right)+t \eta+2 t}{-6 v\left(p_{o n}^{*}\right)+3 v\left(p_{o f f}^{j^{*}}\left(a^{i}\right)\right)+3 v\left(p_{o f f}^{i^{*}}\left(a^{j}\right)\right)} \\
& +2 \pi_{T}^{j}\left(a^{j}\right)+2 \pi_{T}^{i}\left(a^{i}\right)+3 t \eta+3 t
\end{aligned}
$$

Taking derivatives for equally advantaged networks we have 


$$
\frac{\partial x *\left(a^{i}, a^{j}\right)}{\partial a^{i}}=-2 \frac{-a^{i}\left(a^{j}\right)^{2}+(c-1)\left(a^{i}\right)^{2}+\left(2(c-1)^{2}\right) a^{j}+6 t\left(a^{i}-1+c\right)}{\left(-\left(a^{i}\right)^{2}-\left(a^{j}\right)^{2}-2(1-c)\left(a^{i}+a^{j}\right)+12 t\right)^{2}}>0
$$

and

$$
\frac{\partial x *\left(a^{i}, a^{j}\right)}{\partial a^{j}}=-2 \frac{-\left(a^{i}\right)^{2} a^{j}+(c-1)\left(a^{j}\right)^{2}+\left(2(c-1)^{2}\right) a^{i}+6 t\left(a^{j}-1+c\right)}{\left(-\left(a^{i}\right)^{2}-\left(a^{j}\right)^{2}-2(1-c)\left(a^{i}+a^{j}\right)+12 t\right)^{2}}<0
$$

for sufficiently large $t$, as $a^{i}, a^{j}<1-c$ by assumption. q.e.d.

Proof of Lemma 4: Demand cross elasticities of network $i$ are defined as percentage changes of scale (aggregate demand) over percentage changes in network $j$ 's prices. For on-net prices we have

$$
\varepsilon_{x, p_{o n}^{*}}=\frac{\partial x *\left(a^{i}, a^{j}\right)}{\partial p_{o n}^{*}} \times \frac{p_{o n}^{*}}{x^{*}\left(a^{i}, a^{j}\right)}=\frac{\% \Delta x^{*}\left(a^{i}, a^{j}\right)}{\% \Delta p_{o n}^{*}}
$$

with

$$
\frac{\partial x^{*}\left(a^{i}, a^{j}\right)}{\partial p_{o n}^{*}}<0
$$

so that calls from firm $i$ and on-net calls of firm $j$ are complementary. For off-net prices we have

$$
\varepsilon_{x, p_{o f f}^{j^{*}}\left(a^{i}\right)}=\frac{\partial x^{*}\left(a^{i}, a^{j}\right)}{\partial p_{o f f}^{j^{*}}\left(a^{i}\right)} \times \frac{p_{o f f}^{j^{*}}\left(a^{i}\right)}{x^{*}\left(a^{i}, a^{j}\right)}=\frac{\% \Delta x *\left(a^{i}, a^{j}\right)}{\% \Delta p_{o f f}^{j^{*}}\left(a^{i}\right)}
$$

with

$$
\frac{\partial x *\left(a^{i}, a^{j}\right)}{\partial p_{o f f}^{j^{*}}}>0
$$

so that calls from firm $i$ and off-net calls of firm $j$ are substitutes. As a high $t$ will allow to control the magnitude of first derivative term, with $x^{*}$ converging the strictly positive constant, i.e., $\lim _{\eta \rightarrow \infty} x^{*}\left(a^{i}, a^{j}\right)=(2+\eta) /(3+3 \eta)$, we see that a higher access charge $a^{i}$ will be passed on directly into $p_{o f f}^{j^{*}}\left(a^{i}\right)$ thus increasing the demand cross elasticity that network $i$ faces. q.e.d.

Proof of Lemma 5: From (41) we have the equilibrium scale as

$$
\begin{aligned}
&-3 v\left(p_{o n}^{*}\right)+2 v\left(p_{o f f}^{i^{*}}\left(a^{j}\right)\right)+v\left(p_{o f f}^{j^{*}}\left(a^{i}\right)\right) \\
& x *\left(a^{i}, a^{j}, \eta\right)=+\pi_{T}^{i}\left(a^{i}\right)+\pi_{T}^{j}\left(a^{j}\right)+t \eta+2 t \\
&-6 v\left(p_{o n}^{*}\right)+3 v\left(p_{o f f}^{j^{*}}\left(a^{i}\right)\right)+3 v\left(p_{o f f}^{i^{*}}\left(a^{j}\right)\right) \\
&+2 \pi_{T}^{j}\left(a^{j}\right)+2 \pi_{T}^{i}\left(a^{i}\right)+3 t \eta+3 t
\end{aligned}
$$


Taking the derivative we find that $x^{*}\left(a^{i}, a^{j}, \eta\right)$ is strictly decreasing in $\eta$ if

$$
t>v\left(p_{o n}^{*}\right)-v\left(p_{o f f}^{i^{*}}\left(\bar{a}^{j}\right)\right)-\frac{1}{3}\left(\pi_{T}^{i}\left(a^{i}\right)+\pi_{T}^{j}\left(a^{j}\right)\right)
$$

and as $\lim _{\eta \rightarrow \infty} x^{*}\left(a^{i}, a^{j}, \eta\right)=1 / 3$ it has a strictly positive lower bound in $\eta$. q.e.d.

Proof of Lemma 6: Demand elasticities of network $j$ are defined as percentage changes of scale (aggregate demand) over percentage changes in the network's prices. For on-net prices we have

$$
\varepsilon_{x, p_{o n}^{*}}=\frac{\partial\left(1-x^{*}\left(a^{i}, a^{j}\right)\right)}{\partial p_{o n}^{*}} \times \frac{p_{o n}^{*}}{1-x^{*}\left(a^{i}, a^{j}\right)}=\frac{\% \Delta\left(1-x *\left(a^{i}, a^{j}\right)\right)}{\% \Delta p_{o n}^{*}}
$$

and for off-net prices we have

$$
\varepsilon_{x, p_{o f f}^{j^{*}}\left(a^{i}\right)}=\frac{\partial\left(1-x^{*}\left(a^{i}, a^{j}\right)\right)}{\partial p_{o f f}^{j^{*}}\left(a^{i}\right)} \times \frac{p_{o f f}^{j^{*}}\left(a^{i}\right)}{1-x^{*}\left(a^{i}, a^{j}\right)}=\frac{\% \Delta\left(1-x^{*}\left(a^{i}, a^{j}\right)\right)}{\% \Delta p_{o f f}^{j^{*}}\left(a^{i}\right)}
$$

From (41) we see that a high $\eta$ will allow to control the magnitude of first derivative term, with $x^{*}$ converging to some strictly positive constant, we see that a high asymmetry parameter implies $\% \Delta^{*} \rightarrow 0$ and thus $\varepsilon_{x, p_{o n}^{*}}, \varepsilon_{x, p_{o f f}^{j^{*}}\left(a^{i}\right)} \rightarrow 0$. q.e.d.

Proof of Lemma 7: Using the best responses $G^{i}$ and $G^{j}$ from Proposition 2 we find an optimal scale $x^{*}$ that solves the system of equations simultaneously. Firm $i$ 's post-entry profit at this first stage can be written as

$$
\Pi^{i}+F=\left\{\left(x *\left(a^{i}, a^{j}\right)\right)^{2} \times\left[\begin{array}{l}
t(1+\eta)-2 v\left(p_{o n}^{*}\right)+v\left(p_{\text {off }}^{j^{*}}\left(a^{i}\right)\right) \\
+v\left(p_{\text {off }}^{i^{*}}\left(a^{j}\right)\right)+\pi_{T}^{i}\left(a^{i}\right)
\end{array}\right]\right\}
$$

Using the product rule we find that optimal non-reciprocal access charges of firm $i$ necessarily satisfies

$$
\begin{aligned}
& 2 x^{*}\left(a^{i}, a^{j}\right) \frac{\partial x *\left(a^{i}, a^{j}\right)}{\partial a^{i}}\left[\begin{array}{l}
t(1+\eta)-2 v\left(p_{o n}^{*}\right) \\
+v\left(p_{o f f}^{j^{*}}\left(a^{i}\right)\right)+v\left(p_{o f f}^{i^{*}}\left(a^{j}\right)\right)+\pi_{T}^{i}\left(a^{i}\right)
\end{array}\right] \\
& =-\left(x^{*}\left(a^{i}, a^{j}\right)\right)^{2} \frac{\partial\left(v\left(p_{o f f}^{j^{*}}\left(a^{i}\right)\right)+\pi_{T}^{i}\left(a^{i}\right)\right)}{\partial a^{i}}
\end{aligned}
$$

Note that

$$
\frac{\partial\left(v\left(p_{o f f}^{j^{*}}\left(a^{i}\right)\right)+\pi_{T}^{i}\left(a^{i}\right)\right)}{\partial a^{i}}=c_{0}+a^{i}
$$

so that as $\eta$ goes out of bounds we have that 


$$
2\left(\frac{1}{3}\right) \frac{\partial x^{*}\left(a^{i}, a^{j}\right)}{\partial a^{i}}\left[\begin{array}{l}
t(1+\eta)-2 v\left(p_{o n}^{*}\right)+ \\
v\left(p_{\text {off }}^{j^{*}}\left(a^{i}\right)\right)+v\left(p_{\text {off }}^{i^{*}}\left(a^{j}\right)\right)+\pi_{T}^{i}\left(a^{i}\right)
\end{array}\right] \approx\left(\frac{1}{3}\right)^{2}\left(a^{i}-c_{0}\right)
$$

has to hold. As now

$$
\frac{\partial x^{*}\left(a^{i}, a^{j}\right)}{\partial a^{i}}\left[\begin{array}{l}
t(1+\eta)-2 v\left(p_{o n}^{*}\right)+v\left(p_{o f f}^{j^{*}}\left(a^{i}\right)\right) \\
+v\left(p_{o f f}^{i^{*}}\left(a^{j}\right)\right)+\pi_{T}^{i}\left(a^{i}\right)
\end{array}\right] \approx \frac{1}{9}(1-c)-\frac{7}{18}\left(a^{i}-c_{0}\right)
$$

we find

$$
a^{i} \approx c_{0}+\frac{2}{7}(1-c)
$$

approximates the equilibrium access charge in our setting.

Similarly for the strongly advantaged firm $j$ post-entry profits are

$$
\Pi^{j}+F=\left\{\left(1-x^{*}\left(a^{i}, a^{j}\right)\right)^{2} \times\left[\begin{array}{l}
t(1+\eta)-2 v\left(p_{o n}^{*}\right)+v\left(p_{o f f}^{i^{*}}\left(a^{j}\right)\right) \\
+v\left(p_{o f f}^{j^{*}}\left(a^{i}\right)\right)+\pi_{T}^{j}\left(a^{j}\right)
\end{array}\right]\right\}
$$

so that the optimal access charge $a^{j}$ necessarily satisfies

$$
\begin{aligned}
& 2\left(1-x^{*}\left(a^{i}, a^{j}\right)\right) \frac{\partial\left(-x *\left(a^{i}, a^{j}\right)\right)}{\partial a^{j}}\left[\begin{array}{l}
t(1+\eta)-2 v\left(p_{o n}^{*}\right)+v\left(p_{o f f}^{i^{*}}\left(a^{j}\right)\right) \\
+v\left(p_{o f f}^{j^{*}}\left(a^{i}\right)\right)+\pi_{T}^{j}\left(a^{j}\right)
\end{array}\right] \\
& =-\left(1-x^{*}\left(a^{i}, a^{j}\right)\right)^{2} \frac{\partial\left(v\left(p_{o f f}^{i *}\left(a^{j}\right)\right)+\pi_{T}^{j}\left(a^{j}\right)\right)}{\partial a^{j}}
\end{aligned}
$$

and hence as $\eta$ goes out of bounds we have that

$$
2\left(1-\frac{1}{3}\right) \frac{\partial\left(-x^{*}\left(a^{i}, a^{j}\right)\right)}{\partial a^{j}}\left[\begin{array}{l}
t(1+\eta)-2 v\left(p_{o n}^{*}\right)+v\left(p_{o f f}^{i^{*}}\left(a^{j}\right)\right) \\
+v\left(p_{o f f}^{j^{*}}\left(a^{i}\right)\right)+\pi_{T}^{j}\left(a^{j}\right)
\end{array}\right] \approx\left(\frac{2}{3}\right)^{2}\left(a^{j}-c_{0}\right)
$$

has to hold. As now

$$
\frac{\partial\left(-x^{*}\left(a^{i}, a^{j}\right)\right)}{\partial a^{j}}\left[\begin{array}{l}
t(1+\eta)-2 v\left(p_{o n}^{*}\right)+v\left(p_{o f f}^{i^{*}}\left(a^{j}\right)\right) \\
+v\left(p_{o f f}^{j^{*}}\left(a^{i}\right)\right)+\pi_{T}^{j}\left(a^{j}\right)
\end{array}\right] \approx \frac{2}{9}(1-c)-\frac{1}{9}\left(a^{j}-c_{0}\right)
$$

we find the approximation

$$
a^{j} \approx c_{0}+\frac{1}{2}(1-c)
$$

as was to be shown. q.e.d.

Proof of Lemma 8: Let the network with the exogenous advantage $\eta>1$ be network $j$. Then given the advantage is sufficiently large we find from the previous result that the 
marginal consumers is located at $1 / 3$ on the unit interval. The optimal access charge markups approximately satisfy

$$
\Delta^{j^{*}}(x) \approx \frac{1}{2}(1-c)>\Delta^{i^{*}}(x) \approx \frac{2}{7}(1-c)
$$

and by replacing the arguments we find

$$
v\left(p_{\text {on }}^{*}\right) \approx \frac{1}{2}(1-c)^{2}
$$

and

$$
v\left(p_{o f f}^{i^{*}}\left(a^{j^{*}}\right)\right) \approx \frac{1}{8}(1-c)^{2}
$$

and

$$
v\left(p_{o f f}^{j^{*}}\left(a^{i^{*}}\right)\right) \approx \frac{25}{98}(1-c)^{2}
$$

and

$$
\pi_{T}^{i}\left(a^{i^{*}}\right) \approx \frac{10}{49}(1-c)^{2}
$$

and

$$
\pi_{T}^{j}\left(a^{j^{*}}\right) \approx \frac{1}{4}(1-c)^{2}
$$

If $\eta$ is sufficiently large, optimal fixed charges satisfy

$$
G^{j^{*}}>G^{i^{*}}
$$

as the last terms in $G^{j^{*}}$ and $G^{i^{*}}$ dominate and

$$
\left(2\left(\frac{1}{3}\right)(\eta+1)-1\right) t>\left(2+\eta-2\left(\frac{1}{3}\right)(\eta+1)\right) t
$$

or

$$
\frac{2}{3} \eta-\frac{1}{3}>\frac{1}{3} \eta+\frac{4}{3}
$$

always holds. Trivially total profits are larger for the advantaged firm. q.e.d.

Proof of Lemma 9: The necessary condition (25) can be rewritten as

$$
\frac{\partial \pi_{T}^{i}\left(a^{i}\right)}{\partial a^{i}} \frac{1}{q_{o f f}^{j}\left(a^{i}\right)}=\frac{3}{5}
$$

And at the monopoly termination charge the LHS is zero and the RHS is strictly positive. Using 


$$
\frac{\partial \pi_{T}^{i}\left(\Delta^{i}\right)}{\partial \Delta^{i}}=q_{o f f}^{j}\left(\Delta^{i}\right)+\Delta^{i} \frac{\partial q_{o f f}^{j}\left(\Delta^{i}\right)}{\partial \Delta^{i}}
$$

the LHS becomes

$$
1+\frac{\partial q_{o f f}^{j}\left(a^{i}\right)}{\partial \Delta^{i}} \frac{\Delta^{i}}{q_{o f f}^{j}\left(a^{i}\right)} \equiv 1+\varepsilon_{\Delta^{i}}
$$

so that conversely the LHS is greater than the RHS for general demand specifications if $\Delta^{i} \rightarrow 0$ or if demand is very inelastic. q.e.d.

Proof of Proposition 10: Again firm $i$ 's post-entry profit level at the first stage can be written as

$$
\Pi^{i}+F=\left\{\left(x^{*}\left(a^{i}, a^{j}, \eta\right)\right)^{2} \times\left[\begin{array}{l}
t(1+\eta)-2 v\left(p_{o n}^{*}\right)+v\left(p_{o f f}^{j^{*}}\left(a^{i}\right)\right) \\
+v\left(p_{\text {off }}^{i^{*}}\left(a^{j}\right)\right)+\pi_{T}^{i}\left(a^{i}\right)
\end{array}\right]\right\}
$$

The optimal non-reciprocal access charge of firm $i$ for any degree of asymmetry $\eta>0$ necessarily satisfy

$$
\begin{aligned}
\frac{\partial \Pi^{i}(\eta)}{\partial a^{i}}= & 2\left(x *\left(a^{i}, a^{j}, \eta\right)\right) \frac{\partial x^{*}\left(a^{i}, a^{j}, \eta\right)}{\partial a^{i}}\left[\begin{array}{c}
t(1+\eta)-2 v\left(p_{o n}^{*}\right)+v\left(p_{o f f}^{j^{*}}\left(a^{i}\right)\right) \\
+v\left(p_{o f f}^{i^{*}}\left(a^{j}\right)\right)+\pi_{T}^{i}\left(a^{i}\right)
\end{array}\right] \\
& +\left(x^{*}\left(a^{i}, a^{j}, \eta\right)\right)^{2} \frac{\partial\left(v\left(p_{\text {off }}^{j^{*}}\left(a^{i}\right)\right)+\pi_{T}^{i}\left(a^{i}\right)\right)}{\partial a^{i}}=0
\end{aligned}
$$

Setting $c_{0}=0$ from here to simplify notation somewhat we find that a solution necessarily has to satisfy

$$
x *\left(a^{i}, a^{j}, \eta\right)\left(\begin{array}{l}
-a^{i} x *\left(a^{i}, a^{j}, \eta\right)+ \\
\frac{\partial x *\left(a^{i}, a^{j}, \eta\right)}{\partial a^{i}}\left(a^{j}\left(a^{j}-2(1-c)-\left(a^{i}\right)^{2}+2 t(1+\eta)\right)\right.
\end{array}\right)=0
$$

and for an interior solution

$$
\begin{aligned}
\Phi^{i}(\eta) \equiv & -a^{i} x *\left(a^{i}, a^{j}, \eta\right) \\
& +\frac{\partial x^{*}\left(a^{i}, a^{j}, \eta\right)}{\partial a^{i}}\left(a^{j}\left(a^{j}-2(1-c)-\left(a^{i}\right)^{2}+2 t(1+\eta)\right)=0\right.
\end{aligned}
$$

Post-entry profits for the other firm are

$$
\Pi^{j}+F=\left\{\left(1-x^{*}\left(a^{i}, a^{j}, \eta\right)\right)^{2} \times\left[\begin{array}{l}
t(1+\eta)-2 v\left(p_{o n}^{*}\right)+v\left(p_{o f f}^{i^{*}}\left(a^{j}\right)\right) \\
+v\left(p_{o f f}^{j^{*}}\left(a^{i}\right)\right)+\pi_{T}^{j}\left(a^{j}\right)
\end{array}\right]\right\}
$$

Note that the profit terms are fully symmetric except for the own scale scalar. We find that a solution to the optimal non-reciprocal access charge of firm $j$ necessarily satisfies the first order condition 


$$
\left(x *\left(a^{i}, a^{j}, \eta\right)-1\right)\left(\begin{array}{l}
a^{j}\left(1-x^{*}\left(a^{i}, a^{j}, \eta\right)\right)+ \\
\frac{\partial x^{*}\left(a^{i}, a^{j}, \eta\right)}{\partial a^{j}}\left(a^{i}\left(a^{i}-2(1-c)-\left(a^{j}\right)^{2}+2 t(1+\eta)\right)\right.
\end{array}\right)=0
$$

or for an interior solution

$$
\begin{aligned}
\Phi^{j}(\eta) \equiv & a^{j}\left(1-x^{*}\left(a^{i}, a^{j}, \eta\right)\right) \\
& +\frac{\partial x^{*}\left(a^{i}, a^{j}, \eta\right)}{\partial a^{j}}\left(a^{i}\left(a^{i}-2(1-c)-\left(a^{j}\right)^{2}+2 t(1+\eta)\right)=0\right.
\end{aligned}
$$

Using first-order Taylor expansions of the form

$$
\left.\Phi^{k}(\eta) \approx \Phi^{k}(\eta)\right|_{\eta=1}+\left.\frac{\partial \Phi^{k}(\eta)}{\partial \eta}\right|_{\eta=1}(\eta-1) \forall k=i, j
$$

and $i \neq j$ for $\eta$ close to 1 , i.e., around the symmetric equilibrium, we find the linearised simultaneous equation system for an interior solution can be approximated by

$$
\begin{aligned}
0= & -x *\left(a^{i}, a^{j}, \eta\right) a^{i}+\left.\frac{\partial x^{*}\left(a^{i}, a^{j}, \eta\right)}{\partial a^{i}}\right|_{\eta=1}\left(4 t-\left(a^{i}\right)^{2}-a^{j}\left(2(1-c)-a^{j}\right)\right) \\
& +\left(\begin{array}{l}
\partial \frac{\partial x^{*}\left(a^{i}, a^{j}, \eta\right)}{\partial a^{i}} /\left.\partial \eta\right|_{\eta=1}\left(4 t-\left(a^{i}\right)^{2}-a^{j}\left(2(1-c)-a^{j}\right)\right) \\
-\left.\frac{\partial x^{*}\left(a^{i}, a^{j}, \eta\right)}{\partial \eta}\right|_{\eta=1} a^{i}+\left.\frac{\partial x^{*}\left(a^{i}, a^{j}, \eta\right)}{\partial a^{i}}\right|_{\eta=1} 2 t
\end{array}\right)
\end{aligned}
$$

and symmetrically

$$
\begin{aligned}
0= & \left(1-x *\left(a^{i}, a^{j}, \eta\right)\right) a^{j}+\left.\frac{\partial x^{*}\left(a^{i}, a^{j}, \eta\right)}{\partial a^{j}}\right|_{\eta=1}\left(4 t-\left(a^{j}\right)^{2}-a^{i}\left(2(1-c)-a^{i}\right)\right) \\
& +\left(\begin{array}{l}
\partial \frac{\partial x^{*}\left(a^{i}, a^{j}, \eta\right)}{\partial a^{j}} /\left.\partial \eta\right|_{\eta=1}\left(4 t-\left(a^{j}\right)^{2}-a^{i}\left(2(1-c)-a^{i}\right)\right) \\
-\left.\frac{\partial x^{*}\left(a^{i}, a^{j}, \eta\right)}{\partial \eta}\right|_{\eta=1} a^{j}+\left.\frac{\partial x *\left(a^{i}, a^{j}, \eta\right)}{\partial a^{j}}\right|_{\eta=1} 2 t
\end{array}\right)
\end{aligned}
$$

From the above lemma for the symmetric equilibrium $\eta=1$ we find that for large $t$ we have

$$
0=-x *\left(a^{i}, a^{j}, 1\right) a^{i}+\left.\frac{\partial x^{*}\left(a^{i}, a^{j}, 1\right)}{\partial a^{i}}\right|_{\eta=1}\left(4 t-\left(a^{i}\right)^{2}-a^{j}\left(2(1-c)-a^{j}\right)\right)
$$

where the two terms in the RHS product are positive and the RHS is strictly decreasing in $a^{i}$ for given $a^{j}$ and 


$$
0=\left(1-x *\left(a^{i}, a^{j}, 1\right)\right) a^{j}+\left.\frac{\partial x^{*}\left(a^{i}, a^{j}, 1\right)}{\partial a^{j}}\right|_{\eta=1}\left(4 t-\left(a^{j}\right)^{2}-a^{i}\left(2(1-c)-a^{i}\right)\right)
$$

where the first term in the RHS product is negative, the second positive, and the RHS is strictly increasing in $a^{j}$ for given $a^{i}$. Thus, for large $t, c_{0} \geq 0$ and $\eta=1$ we find

$$
a^{i}-c_{0}, a^{j}-c_{0}>0
$$

has to hold for the system to be satisfied so that markups are strictly positive.

For any $\eta>0$ and large $t$ we have the approximate system of (84) and (85) given by the best response functions

$$
\begin{aligned}
0= & -x *\left(a^{i}, a^{j}, 1\right) a^{i}+\left.\frac{\partial x^{*}\left(a^{i}, a^{j}, 1\right)}{\partial a^{i}}\right|_{\eta=1}\left(4 t-\left(a^{i}\right)^{2}-a^{j}\left(2(1-c)-a^{j}\right)\right) \\
& +\frac{1}{18}\left(-1+c+\frac{1}{2} a^{i}\right)(\eta-1)
\end{aligned}
$$

and symmetrically

$$
\begin{aligned}
0= & \left(1-x *\left(a^{i}, a^{j}, 1\right)\right) a^{j}+\left.\frac{\partial x^{*}\left(a^{i}, a^{j}, 1\right)}{\partial a^{j}}\right|_{\eta=1}\left(4 t-\left(a^{j}\right)^{2}-a^{i}\left(2(1-c)-a^{i}\right)\right) \\
& +\frac{1}{18}\left(-1+c+\frac{1}{2} a^{j}\right)(\eta-1)
\end{aligned}
$$

as by assumption, $a^{i}, a^{j}<1-c$ we find that the additional term for $\eta>1$ is strictly negative. Hence, for $\eta$ slightly above one, $a^{j}$ has to increase by more than $a^{i}$ in order to keep the simultaneous equation system satisfied. If the advantage is reversed, i.e., $\eta<1$ then the additional term is positive and $a^{i}$ has to increase by more than $a^{j}$. q.e.d.

Lemma 11: The own second partial derivatives with regard to scale is negative for any access charges $\left(a^{i}, a^{j}\right)$ if

$$
t(1-\eta)>2 v\left(p_{\text {on }}^{*}\right)
$$

and the condition is sufficient for post-entry profits for networks $i, j$, to be strictly positive.

Proof of Lemma 11: The own second partial derivatives with respect to the optimal scale are

$$
\frac{\partial^{2} \Pi^{i}}{\partial x^{2}}=4 v\left(p_{o n}^{*}\right)-2 t(1+\eta)-2 v\left(p_{o f f}^{i^{*}}\left(a^{j}\right)\right)-2 v\left(p_{o f f}^{j^{*}}\left(a^{i}\right)\right)-2 \pi_{T}^{i}\left(a^{i}\right)
$$

and

$$
\frac{\partial^{2} \Pi^{j}}{\partial x^{2}}=4 v\left(p_{o n}^{*}\right)-2 t(1+\eta)-2 v\left(p_{o f f}^{j^{*}}\left(a^{i}\right)\right)-2 v\left(p_{o f f}^{i^{*}}\left(a^{j}\right)\right)-2 \pi_{T}^{j}\left(a^{j}\right)
$$


so that the condition is sufficient for the second derivative to be negative for $a n y a^{i}, a^{j}$. By observation, given the optimal post-entry profit functions (53) and (59) we find that the sufficiency result follows. q.e.d.

Lemma 12: The own second partial derivatives with regard to the access charges $\left(a^{i}, a^{j}\right)$ given the price vector choices $\Xi^{i}, \Xi^{j}$ at stage one are negative if the value of the pure benefit of being connected $t$ and/or the degree of asymmetry $\eta$ is sufficiently large.

Proof of Lemma 12: Taking derivatives we find

$$
\begin{aligned}
& \lim _{\eta \rightarrow \infty}\left(\frac{\partial^{2} \Pi^{i}\left(p_{o n}^{i^{*}}, p_{o f f}^{i^{*}}, G^{i^{*}} ; \Xi^{j^{*}}, a^{j}\right)}{\partial\left(a^{i}\right)^{2}}\right) \\
& =\lim _{\eta \rightarrow \infty}\left(\begin{array}{l}
-x^{*}\left(a^{i}, a^{j}, \eta\right)^{2}-4 \frac{\partial x *\left(a^{i}, a^{j}, \eta\right)}{\partial a^{i}} a^{i} x^{*}\left(a^{i}, a^{j}, \eta\right) \\
\left.+\left(a^{i}, a^{j}, \eta\right) \partial \frac{\partial x^{*}\left(a^{i}, a^{j}, \eta\right)}{\partial a^{i}} / \partial a^{i}+\left(\frac{\partial x *\left(a^{i}, a^{j}, \eta\right)}{\partial a^{i}}\right)^{2}\right) \\
\times\left(2 t+2 t \eta-2 a^{j}+2 c a^{j}+\left(a^{j}\right)^{2}-\left(a^{i}\right)^{2}\right)
\end{array}\right) \\
& =\lim _{\eta \rightarrow \infty}\left(\frac{\partial^{2} \Pi^{j}\left(p_{o n}^{j^{*}}, p_{o f f}^{j^{*}}, G^{j^{*}} ; \Xi^{i^{*}}, a^{i}\right)}{\partial\left(a^{j}\right)^{2}}\right)=-\frac{16}{27}<0 \forall t
\end{aligned}
$$

Also

$$
\lim _{t \rightarrow \infty}\left(\frac{\partial^{2} \Pi^{j}\left(p_{o n}^{j^{*}}, p_{o f f}^{j^{*}}, G^{j^{*}} ; \Xi^{i^{*}}, a^{i}\right)}{\partial\left(a^{j}\right)^{2}}\right)=-\frac{1}{27} \frac{16 \eta^{2}+22 \eta+7}{(1+\eta)^{2}}<0 \forall \eta
$$

and

$$
\lim _{t \rightarrow \infty}\left(\frac{\partial^{2} \Pi^{i}\left(p_{o n}^{i^{*}}, p_{o f f}^{i^{*}}, G^{i^{*}} ; \Xi^{j^{*}}, a^{j}\right)}{\partial\left(a^{i}\right)^{2}}\right)=-\frac{1}{27} \frac{7 \eta^{2}+22 \eta+16}{(1+\eta)^{2}}<0 \forall \eta
$$

and thus sufficiency follows. q.e.d. 